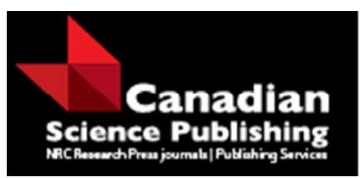

Canadian Journal of Forest Research

Revue canadienne de recherche forestière

\title{
Watershed-scale forest biomass distribution in a perhumid temperate rainforest as driven by topographic, soil, and disturbance variables.
}

\begin{tabular}{|r|l|}
\hline Journal: & Canadian Journal of Forest Research \\
\hline Manuscript ID & cjfr-2016-0041.R2 \\
\hline Manuscript Type: & Article \\
\hline Date Submitted by the Author: & 07-Apr-2016 \\
\hline Keyword: & temperate rainforest, carbon, remote sensing, spatial distribution, biomass \\
\hline & $\begin{array}{l}\text { Kuma, Brian; University of Alaska Southeast, Natural Sciences } \\
\text { Edwards, Richard; United States Forest Service, PNW Research Station }\end{array}$ \\
\hline
\end{tabular}

SCHOLARONE

Manuscripts 
TITLE

i) Watershed-scale forest biomass distribution in a perhumid temperate rainforest as driven by topographic, soil, and disturbance variables.

5

ii) Buma B, Krapek J, Edwards RT

iii) Buma, Brian

Department of Natural Sciences, University of Alaska Southeast.

Brian.Buma@uas.alaska.edu

10

Krapek, John

School of Natural Resources and Extension, University of Alaska Fairbanks.

jpkrapek@alaska.edu

Edwards, Rick T

United States Forest Service, Forest Service Research Lab.

rtedwards@fs.fed.us

iv) Corresponding author: Brian Buma, 11120 Glacier Hwy, Juneau, Alaska, 99801

Brian.Buma@uas.alaska.edu, 907-796-6410 (phone), 907-796-6406 (fax)

20 


\section{ABSTRACT}

22 Temperate rainforests are the most carbon dense forest ecosystem on the planet, with C stocks several

23 times higher than most other forested biomes. While climatic and disturbance drivers of these $\mathrm{C}$ stocks

24 are relatively well explored, the spatial distribution of those stocks at the scale of entire watersheds is

25 less well known, particularly in perhumid rainforests where research has been minimal. This study

26 explored biomass distributions across an entire watershed simultaneously, from ocean to glacial

27 icefields in southeast Alaska. Utilizing LiDAR and ground surveys, biomass was modelled throughout the

28 landscape and distributions described statistically. The dominant driver of biomass distributions at this

29 scale (controlling for elevation) was the flow of water through the landscape - areas of higher water

30 accumulation typically had low biomass (often $<10 \mathrm{Mg} / \mathrm{ha}$ ), whereas well drained areas supported

31 biomass approaching $950 \mathrm{Mg} / \mathrm{ha}$. This relationship was strong at all elevations; only riparian locations

32 (typically well-drained soils) maintained high biomass at low slopes. Exposure to stand replacing

33 disturbances, often a dominant driver, was only a minor factor. This work emphasizes the importance of

34 water in temperate rainforests and the potentially significant impacts of changes to biomass given

35 changes in precipitation (both increasing and decreasing) due to global climate change.

36 KEYWORDS

37 Temperate rainforest, carbon, remote sensing, spatial distribution, biomass 
Temperate rainforests are the most carbon dense forest biome on the planet, sequestering up to 1800

$\mathrm{Mg} \mathrm{C/hectare} \mathrm{in} \mathrm{some} \mathrm{locations} \mathrm{in} \mathrm{aboveground} \mathrm{C}$ alone (Keith et al. 2009). The forests of the northwest

42 North American coast represent approximately half of the remaining temperate rainforests globally ( 27

43 million ha, DellaSala et al. 2011) and high carbon densities (aboveground mean $334 \mathrm{Mg} \mathrm{C/ha;} \mathrm{Keith} \mathrm{et} \mathrm{al.}$

44 2009). Belowground and soil stocks of carbon are often greater than aboveground stocks; the Tongass

45 National Forest (southeast Alaska) alone is estimated to contain $\sim 2.8 \mathrm{Pg}$ C, equivalent to $8 \%$ of the total

forest carbon in the conterminous US and $0.25 \%$ of global forest carbon (Leighty et al. 2006).

47 Because of the global significance of these carbon reservoirs, and the expectations for substantial physical (e.g., freezing days, Meehl et al. 2004) and biological (e.g., yellow cedar decline, Hennon et al. 2012) change due to climate warming, it is important to understand the distribution of those carbon stocks at multiple scales, from stand level controls on forest productivity (e.g., gap dynamics and

51 stochastic single-tree mortality, Alaback 1996; Ott and Juday 2002) to regional assessments of biomass

52 and change (e.g., latitudinal gradients in climate, Buma and Barrett 2015).

53 Here, we assess the distribution of biomass at the landscape scale, from the estuary to the glacial

54 headwaters of an approximately 10,000 ha watershed in the perhumid rainforest of southeast Alaska.

55 Productive portions of these coastal forests are characteristically dense, with estimates of aboveground 56 biomass densities generally from approximately 700-1000 Mg/ha (Waring and Franklin 1979, Smithwick 57 et al. 2004, Matsuzaki et al. 2013), though most research has been in the southern half of the perhumid rainforest biome (British Columbia and Washington/Oregon) and often focused on average biomass of

59 high productivity stands. Other studies primarily focused on biomass variability across those landscapes, 60 identifying several important factors influencing. For example, riparian zones are typically associated 61 with relatively high aboveground biomass, often attributed to better drained soils (Viereck et al. 1983; 
62 Simard et al. 2007), and the influence of marine derived nutrients may influence biomass at fine scales

63 (Helfield and Naiman 2003). The decline of biomass with increasing elevation is well known, and in

64 many high latitude areas, lower average solar radiation (e.g., poleward aspects) is also associated with

65 lower biomass. Disturbance events have a significant, long-term influence on biomass in many systems,

66 especially in areas where disturbances are large relative to the landscape under study (Turner et al.

67 2003); however SE Alaskan perhumid rainforests are typically dominated by a gap phase/non-

68

catastrophic disturbance regime (e.g., single tree mortality, Veblen and Alaback 1996; Ott and Juday 2002). Severe disturbances such as wind and landslides can cause substantial mortality and subsequent impacts on biomass (Veblen and Alaback 1996; Nowacki and Kramer 1998), but area potentially exposed to those events is relatively limited (southeast-facing slopes: wind (Kramer et al. 2001); steep slopes: landslides (Buma and Johnson 2015)) and average canopy turnover time of all aspects is quite long, approximately 575 years (range: $210-920$ years; Ott and Juday 2002). In total, while the importance of these various processes to biomass distributions has been well delineated in a variety of systems, their relative importance in the perhumid temperate rainforest is poorly understood and not systematically explored despite the significance of this region to regional, national, and global carbon budgets.

We were interested in assessing topographic, disturbance, and edaphic drivers simultaneously to explore their relative contribution to biomass distribution in an unmanaged watershed. Despite the importance of these forests, previous research on spatial distributions of biomass has been limited due to access. Little of the landscape is accessible by road, necessitating boat or plane transport, and the terrain is steep and heavily wooded, with substantial amounts of downed debris and often inclement weather. Consequently, descriptions of patterns of biomass density at the landscape scale (e.g., in relation to slope, riparian areas, or elevation) are typically indirect and often limited to field-sampled plots, which may then be scaled using multiple plots spread out over the entire region (e.g., forest inventory and analysis (FIA) plots, Peterson et al. 2014). Alternatively, some carbon assessments utilize 
86 photointerpreted forest age along with plots to estimate biomass distributions (e.g., Leighty et al. 2006).

87 These methods are valid, but suffer from the necessity of making inferences to unsampled areas ("up-

88 scaling errors," Keith et al. 2010). This creates uncertainty when looking at fine spatial scales such as a

89 single watershed.

90 LiDAR is an active remote sensing technique which directly measures attributes of forest structure

91 across wide areas at a fine spatial resolution. This direct measurement avoids the issues associated with

92 correlations based on reflectance or photointerpreted patterns, as all points on the landscape are

93 physically measured. While limited in some applications, LiDAR is particularly useful for biomass

94 estimation and mapping in forests (Mitchard et al. 2013), as biomass is tightly coupled to forest

95 structure; LiDAR measures the structural characteristics of a forest stand at fine resolution (Wulder et al.

96 2012). By relating ground truth biomass measurements to the LiDAR, highly accurate maps of forest

97 biomass can be constructed utilizing the wide coverage of the LiDAR structural measurements (e.g.,

98 Hudak et al. 2012). Using LiDAR, we mapped biomass over an entire watershed simultaneously, from

99 estuary to glacial headwaters, and examined topoedaphic and disturbance associated controls on

100 biomass distribution at this broad scale. The riparian zone is specifically examined in terms of both its

101 association with overall landscape biomass patterns and how it influences the relationship of other

102 topoedaphic/disturbance variables with biomass.

103 Questions:

104 1. How do topoedaphic factors and exposure to disturbances influence biomass distribution across an 105 entire watershed?

106 2. Are the relationships between biomass and topoedaphic drivers/disturbance exposure different in 107 the riparian zone compared to the rest of the landscape? 


\section{Methods}

Site: The study area comprises the Cowee Creek watershed, one broad drainage approximately $60 \mathrm{~km}$ north of Juneau, AK (USA; Lat. 58.65, Long. -134.91), extending from a broad estuarine landscape on the coast to three large watersheds, one of which contains two glaciers (Davies and Quiet glaciers), one a single glacier (Cowee Glacier), and one with no glacial influence; the majority of the landscape is designated as the USFS Héen Latinee Experimental Forest (HLEF). Climate is maritime, with yearly precipitation of $1500-3000+\mathrm{mm}\left(>10 \%\right.$ during the summer) and mean temperatures ranging from $-5^{\circ} \mathrm{C}$ in the winter to $\sim 10-15{ }^{\circ} \mathrm{C}$ in the summer (Alaback 1996). Overstory diversity is low, dominated by Sitka spruce (Picea sitchensis (Bong.)), western and mountain hemlock (Tsuga heterophylla (Raf.) and T. mertensiana (Bong.)), black cottonwood (Populus trichocarpa (Torr. and Gray)), and red and Sitka alder (Alnus rubra (Bong.) and A. viridis (Chaix) spp. sinuata (Regel)), with shore pine (Pinus contorta var. contorta (Dougl.)) dominating in peatlands. Small populations of willows (Salix spp.) and yellow-cedar (Callitropsis nootkatensis (D. Don)) occur in isolated locations.

The Cowee-Davies Creek drainages have not been subjected to widespread industrial timber harvest. During the 1940's approximately 80 ha of timber was clear-cut along Cowee Creek in the lower watershed near the present road (Carstenson 2013). In 1999 approximately 20 ha of timber was clearcut on the northern side of Davies Creek in the lower watershed, and trees were removed by selective harvest on an adjacent area NE of the clearcut. Some timber was likely removed for mine roads and structures along the western edge of Cowee Creek in approximately 1890-1920, but no evidence of such logging is detectable. No evidence of logging was observed on any of the calibration plots (below).

Plot network: Forty seven 20x20m plots were established throughout the HLEF. Location was determined semi-randomly, constrained by access due to the rough terrain of the watershed. After a point was placed, a preliminary 5x5m tree height map derived from the LiDAR was used to locate four 
131 plots around that point; one point was located in each of the following tree height classes: the lowest $13225 \%$ of tree heights, the $25-50 \%$, the $50-75 \%$, and the $75-100 \%$. Because the LiDAR sampling covered 133 the entire watershed, the goal in the plot selection process was sampling the entire range of LiDAR 134 response values. This ensured that although the location of the plots within the landscape was only 135 semi-random and constrained by access/logistical limitations, there was a similar (and comprehensive) 136 range in aboveground biomass in each general area visited, which spanned much of the elevational 137 range present in the forested part of the watershed (maximum elevation $=588 \mathrm{~m}$ ). Each plot was 138 completely surveyed for aboveground biomass. Diameter, species, and health status of all trees $>1.4 \mathrm{~m}$ 139 tall was recorded; a subset also had their height measured using an inclinometer. Stumps and snags 140 (standing dead) trees were recorded; if tops were broken the height of breakage was noted and used to 141 adjust biomass estimates (below). Snag species were recorded whenever possible; if unknown they 142 were assumed to be Sitka spruce for biomass calculations, the most common overstory species. All 143 seedlings were counted by species and grouped into height classes (0-10, 10-20, 20-30, 30-40, 40-50, 144 and $50+\mathrm{cm}$ ). Coarse woody debris (CWD) loading was estimated via two 20m Brown's lines (a line 145 intercept method; Brown 1974) limited to the LiDAR pixel footprint (see below); sound and rotten debris 146 were tallied separately. Because the watershed contains a substantial amount of unvisited glacial area, 14716 points were randomly located on the bare rock/snow/ice field at the top of the watershed; these 148 sites were assigned zero biomass. In total, the final set of ground data used to create the LiDAR biomass 149 map contained 63 sites.

150 These measurements were converted to aboveground biomass utilizing allometrics derived for this 151 ecosystem. Two allometric regression groups (ARGs) were used to check for sensitivity of biomass to 152 different diameter/height/biomass relationship equations, either Standish et al. (1985) or Ter-Mikaelian 153 and Korzukhin (1997). Equations for alder were from Ung et al. (2008) and willow from Brown (1976); 154 both are minor components of the landscape; these were used for both of the ARGs. Biomass estimates 
155 for broken trees were adjusted based on observed breakage height and stem taper equations from

156 Kozak et al. (1969). Seedling biomass was estimated by averaging biomass estimates for each size class

157 using data from Keyser (2008) and D'Amore unpublished data.

158 LiDAR acquisition: LIDAR data were acquired using a Leica ALS50 Phase II system on two dates, 21

159 September and 26 October 2012, by Watershed Sciences Inc., Corvallis OR. Average first return point 160 densities were 7.2 and 7.7 points $\mathrm{m}^{-2}$ on the two dates respectively. Ground classified point densities 161 were 0.81 and 1.73 points $\mathrm{m}^{-2}$. Average absolute vertical accuracy was $3 \mathrm{~mm}$ on both dates, RMSE 162 accuracy was $36 \mathrm{~mm}$. The LiDAR coverage included the entire watershed, and a small buffer extending 163 into neighboring watersheds to avoid edge complications (which was excluded from the final results).

LiDAR processing: The LiDAR data were aggregated at a $20 \mathrm{~m}$ resolution into 61 statistical descriptions of

165 the point cloud, similar to Hudak et al. (2012). For example, in a given $20 \times 20 \mathrm{~m}$ pixel there are

166 approximately 4000 lidar returns. For the median height raster, the median vegetation height value was

167 rasterized, resulting in the median height raster for the entire study region. For the $90^{\text {th }}$ percentile

168 height raster, the $90^{\text {th }}$ percentile vegetation height value was rasterized. Five additional datasets

169 potentially related to biomass were used: Forest type, land cover, precipitation, wind exposure, and

170 landslide susceptibility. For more details and a complete list of metrics, see Supplementary Data 1.

171 To create the landscape scale biomass map, multivariate adaptive regression splines (MARS; Friedman

172 1991) modeling was employed: Observed biomass was modeled based on the observed LiDAR metrics

173 at each point. MARS is a non-parametric modeling framework suitable for high-dimensional data where

174 relationships are not necessarily linear and has been shown to be superior to comparable methods in

175 similar floodplain forests at a 30m scale (Guneralp et al. 2014). It produces a continuous, nonlinear

176 response to the data. However, as the number of terms increases, the potential for overfitting also

177 increases. The MARS model was therefore pruned based on 10 -fold cross validation to avoid 
178

179

180

181

182

183

184

185

186

187

188

189

190

191

192

193

194

195

196

197

198

199

overfitting. In this process, a portion of the dataset is left out of modeling building and used to test model fit. This was done 10 times, using a random subsample of plots for validation each time; the optimal tree size was determined from average $r^{2}$ on the validation points. The final model was then built from all the data points and pruned to that optimal tree size.

Distributional Analyses: We then explored how that biomass was distributed over the landscape in relation to ten topoedaphic variables. Six were related to topography (aspect, slope, solar radiation, contributing area, topographic index, and elevation; data from the NASA ASTER mission), two were related to soil (hydric soils, which are locations that are often water saturated, and riparian areas, assumed to be predominately coarse, well-drained soil; data for both from USFS maps derived from aerial photographs) and two were related to disturbance exposure (exposure to the prevailing storm track and exposure to landslides; Buma and Johnson 2015, Buma and Barrett 2015). These variables were chosen to assess drivers of biomass distribution hypothesized to be relevant to aboveground biomass/CWD at this scale: Elevation, drainage, disturbance, and solar radiation.

For units and references, see Table 1 . Two thousand points were randomly distributed across the study area in R ( $\mathrm{R}$ Core Team 2015). Preliminary analyses indicated that elevation was the most significant predictor variable of biomass (from sea level to icefield), so we regressed the biomass estimates via a cubic linear model, limited the datapoints to below treeline $(<900 \mathrm{~m})$, and conducted subsequent analyses on the residuals of that relationship (for further details, see Supplementary Data 2). This subsetting focused the analysis on variables associated with higher or lower biomass values (1) than would be expected based on elevation alone and (2) excluding the zero biomass points on the icefield, a statistically conservative approach to lower the chance of Type I errors. From this point onward, the term "biomass" refers to this residual biomass number after removing the elevational trend. 
200

201

202

203

204

205

206

207

208

209

210

211

212

213 214 (predicted - observed) was $2.03 \mathrm{Mg} / \mathrm{ha}$ (Standish, Figure 2) and -11.6 Mg/ha (Ter-Mikaelian). The MARS

215

216

217

218

219

220

221

To identify drivers of biomass across the landscape, classification and regression trees (CART, Briemann et al. 1983) were used. Regression trees are useful in describing complex interactions between variables, nonlinear relationships, and are appropriate for non-normally distributed response data. The trees were pruned using 10 -fold cross validation, with tree size being limited by the point where increasing complexity returned minimal $(<0.5 \%)$ error reduction. Finally, to explore potential interactions between the riparian zone and the other variables on biomass, we used ANCOVA models (transformed variables where appropriate) to compare how the various potential drivers of biomass were modified by being inside or outside the riparian zone.

\section{RESULTS}

Biomass mapping \& LiDAR: Final ground data ranged from $0 \mathrm{Mg} / \mathrm{ha}$ to $1115 \mathrm{Mg} / \mathrm{ha}$ using the Standish ARG. The LiDAR data successfully modeled observed total aboveground biomass throughout the landscape for both sets of allometric equations $\left(r^{2}\right.$ : Standish: 76\%, Fig. 3; Ter-Mikaelian: 73\%). Error was normally distributed around zero with no bias, supporting the subsequent use of the map to estimate watershed-scale controls on biomass distribution. Mean error relative to the ground plots model and variable selection procedure isolated vegetation density and the $90^{\text {th }}$ percentile of vegetation height as the most useful predictors (both allometric sets) and discarded the remaining coefficients. The MARS modeling approach was also successful for individual components of that total biomass, though fit was less than the cumulative biomass value. For standing biomass (live and dead), the Standish allometrics were a slightly better fit after cross validation $\left(r^{2}=0.70\right)$ than the Ter-Mikaelian $\left(r^{2}=0.66\right)$. For CWD alone (excluding standing live and dead), the MARS technique was less successful $\left(r^{2}=0.58\right)$. Because the overall results are relatively insensitive to the ARGs, only those for the Standish set of 
222 equations are reported here. In addition, we focus on the cumulative biomass (standing live, standing

223 dead, and CWD). See Appendix 1 for a comparison of the two allometric sets.

224 Biomass distribution modeling: Analysis of the distribution of biomass across the landscape highlighted

225 drainage-relevant variables as the main controls on aboveground biomass after partitioning out

226 elevational relationships (Fig. 4). Both topography and soils were relevant: Slope was the primary

227 driver, as was contributing area (log transformed), both strong influences on drainage and water

228 accumulation, with biomass increasing as drainage rates would be expected to increase. Hydric soils

229 (predominately saturated and often dominated by Sphagnum spp.) were also important, with lower

230 biomass found on hydric soil types. Low slopes were associated with low biomass; even low slope areas

231 not identified with hydric soils had lower biomass than would be expected from elevation alone (though

232 substantial variance does exist). Residual variance for biomass was high $\left(r^{2}:\right.$ Standish $\left.=0.32\right)$. This low $r^{2}$

233 value is conservative, in that a more complex regression tree increases the $r^{2}$ value, however it increases

234 cross-validated error rates. As a result, the more general/conservative, highly pruned tree (minimal

235 splits) is reported.

236 The riparian zone was not an indicator chosen in the regression tree models, nor were there significant

237 differences between riparian and non-riparian zones in terms of detrended biomass. However, the

238 ANCOVA analyses indicated that the relationships between slope, wind exposure, and slide suitability

239 and biomass was significantly influenced by being in the riparian zone. This is apparent in the slope vs.

240 residual biomass plot (Fig. 5). At low slopes, riparian zones are approximately normally distributed with

241 respect to biomass, whereas non-riparian areas at low slopes have substantial negative values,

242 indicating much less biomass than what would be expected based on elevation alone.

243 Discussion: 
244 This study investigated the distribution of total aboveground biomass (standing (live and dead) and

245 downed) in a complete perhumid temperate rainforest system, from the estuary to glacial headwaters,

246 at a high spatial resolution. The use of LiDAR and the particular nature of the study area, which

247 progresses from marine tidal areas to glaciers in a short horizontal distance, allows for a synoptic view of

248 the entire watershed landscape and simultaneous evaluation of a variety of drivers of biomass

249 distribution. Areas with the highest density of aboveground biomass (live, standing dead, and CWD) on

250 the landscape (e.g. 750-949 Mg/ha; Fig. 3) were similar to values from previous research in the same

251 species assemblages further south in the biome (examples: $690 \mathrm{Mg} / \mathrm{ha}$ [Matsuzaki et al. 2013, assuming

252 biomass $~ 50 \%$ C], $789 \mathrm{Mg} / \mathrm{ha}$ [Waring and Franklin 1979], $815 \mathrm{Mg} / \mathrm{ha}$ [Trofymow and Blackwell 1998],

$253956 \mathrm{Mg} / \mathrm{ha}$ [Smithwick et al. 2004, assuming biomass 50\% C]), confirming the expectation that

254 aboveground biomass is generally dense in productive, old stands. Variation in that value, however, was

255 apparent at the $20 \mathrm{~m}$ scale across the watershed (Fig. 3). Unsurprisingly for a study area that covers sea

256 level to glaciers, the major correlate of biomass distribution within the watershed was elevation (Fig. 3).

257 Peak biomass on well drained slopes began to decline above $\sim 400 \mathrm{~m}$ and dropped to near zero above

$258850 \mathrm{~m}$ (Supplemental Data 2). This roughly corresponds to a switch from Sitka spruce and western

259 hemlock dominance to mountain hemlock dominance, though all species can be found across most of

260 the elevational gradient.

261 Analysis of both allometric maps (Fig. 4, Appendix 1 Fig. A1-1) suggests that the dominant control on

262 aboveground biomass in perhumid rainforests, after controlling for elevation, is how long water is

263 retained in the soil. Slope, hydric soils (predominately peatlands, and signifying areas where water

264 accumulates), and contributing area were the dominant drivers of biomass variation, with steeper

265 slopes, non-hydric soils, and lower contributing area all leading to higher biomass totals. This confirms

266 expectations that in regions of high precipitation (e.g., $>2000+\mathrm{mm} /$ year), drainage/water accumulation

267 is critical to aboveground carbon balance (Bisbing et al. 2015). This is likely due to decreased 
268

269

270

271

272

273

274

275

276

277

278

279

280

281

282

283

284

285

286

287

productivity in wet areas (lower NPP due to water logging). A comparison of old growth stands in British Columbia on well drained and poorly drained soils also found slightly higher biomass in better draining soils, despite being in an area with much less precipitation $(930 \mathrm{~mm}$ vs. $1500-3000+\mathrm{mm}$, Fredeen et al. 2005). Alternatively, it could result from increased mortality (e.g., anoxic conditions, less windfirmness, more stem rots) - however, increased wind exposure was associated with higher rather than lower biomass, and areas that had topographic shelter from the storms had lower biomass. This is consistent with the drainage hypothesis, as wind disturbance results in soil disruption (e.g., tip-up mounds) which can increase soil drainage and alter nutrient cycling (Kimmins 1996; Kramer et al. 2004). Increasing landslide suitability likewise resulted in increased biomass. This could be due to disturbance, but must be interpreted cautiously; most of the landscape has a relatively low landslide suitability score and that score is directly related to both slope and drainage metrics (Buma and Johnson 2015) and so the confounding influence with those variables is possible. In the case of landslide suitability, the difference was, in any case, relatively minimal.

Overall, the topoedaphic and disturbance variables only explained a portion of the variance in the biomass residuals (Fig. 3). This can be explained in two ways, one statistical/methodological and one ecological. Statistically, the regression trees are conservative, and seek to avoid overfitting by limiting the number of splits via cross validation. A more complex tree would fit the data more closely (resulting more splits, with smaller numbers of points in each terminal node) and thus return higher $r^{2}$ values, but would decrease the generalizability of the results. The similarity of results between the ARGs (Appendix 1) indicates that the results are an accurate representation of general biomass patterns.

Ecologically, the forest is dominated by a gap dynamic regime (Alaback 1996; Ott and Juday 2002; Buma and Barrett 2015), with single tree mortality occurring via stem rot and snapping. While we considered exposure to stand replacing events in our modelling, background mortality from this single tree death 
291 (e.g., senescence, heart rot, etc.) cannot be accounted for. Because the trees are large ( $>1 \mathrm{~m}$ DBH, >60m

292 height), they comprise a significant portion of any given pixel. Thus a single tree dying or falling will

293 have a substantial impact on observed biomass at any given point (regardless of topoedaphic position)

294 as a function of individual tree age; this is essentially "inherent variability" at fine scales. While this

295 mortality should be partially captured by our estimates of coarse woody debris biomass, which is

296 incorporated into the total aboveground biomass estimates, the LiDAR data were very limited in their

297 ability to model CWD alone (data not shown). This is likely due to the characteristically thick surface

298 organic component and often thick and continuous understory layer, with moss and rapid humus

299 formation obscuring the CWD from the LiDAR (in other words, the CWD surfaces may be confused for

300 the ground). One alternative would be carrying out the analyses at a coarser resolution (e.g., 50m

301 pixels) to further reduce the influence of single tree mortality. However, this would reduce spatial

302 precision, especially on significant boundaries such as the edges of peatlands, the bottoms of slopes,

303 and at treeline. Therefore we opted to retain the variance (box plots in Fig. 3) and propose that much of

304 that residual variance is explained by site to site variation in single tree mortality surrounding the mean

305 values driven by the topoedaphic and disturbance exposure values we modeled (the nodes of the tree in 306 Fig. 4).

307 The lack of major influence of the riparian zone on biomass residuals directly (at this scale) was

308 unexpected. Both main streams support strong salmon runs within the areas considered riparian, with

309 several species of salmon making yearly migrations. Salmon, and their associated influx of marine

310 derived nutrients (MDN) into forested systems, have long been hypothesized as drivers of riparian

311 productivity and biodiversity (e.g., Helfield and Naiman 2003; Muehlbauer et al. 2014). There was no

312 evidence of a significant MDN-productivity relationship at this scale, which would be expected to result

313 in substantially higher biomass in riparian zones. Flooding disturbance is also a potential issue, as there

314 could be higher productivity but also higher biomass turnover rates. As CWD was measured, any dead 
315 material would need to be removed from the system to have not been included in estimates. The

316 relatively small size of the watershed and river (mean annual flow rate of $8 \mathrm{~m}^{3} / \mathrm{s}$ at mouth), however,

317 make that hypothesis less likely, though an investigation of relative growth rates is needed to

318 conclusively address that possibility.. In the end, the lack of inclusion of riparian zonation in the CART

319 regression indicates that biomass changes with elevation similarly in riparian and non-riparian areas.

320 The riparian zones in the study region are all relatively low elevation, however, and it is unknown if the

321 relationships would be similar at higher elevations.

322 Riparian zones did, however, change the relationship between other topoedaphic predictors and

323 biomass. Biomass was higher in riparian areas relative to non-riparian areas in areas of lower slopes

324 and higher wind/landslide exposure $(p<0.05)$. The difference was seen in low slope areas $(<10$

325 degrees), which typically had low biomass (Fig. 5), resulting from excess water/often poor drainage, and

326 resultant low growth and/or peatland presence (Bisbing et al. 2015). Riparian areas, with

327 characteristically coarse alluvial soils, are typically well drained, reducing the potential for hypoxic

328 conditions even at low slopes (Kimmins 1996, Alaback 1996). This characteristic, together with our

329 observations of low biomass in most low slope areas further supports the hypothesis that biomass is

330 primarily controlled by drainage. The coarser soils allow for deeper rooting, allowing for more biomass

331 in wind and potential landslide areas by increasing forest resistance to disturbance (Ray and Nicoll 1998;

332 Mitchell 2012). Analysis of tree ages would be necessary to determine if the riparian zone is, in this

333 case, increasing forest resistance to disturbance, and would need to be coupled with estimations of

334 mortality by other factors (e.g., fungal infections). However, that we observed low biomass in non-

335 riparian low slope areas protected from storm winds and landslides suggests drainage is more

336 significant. 
337 Uncertainties: As with all remote sensing based studies, several caveats exist. Plot locations were

338 located according to a semi-random design intended to sample the range of potential biomass totals

339 and across the range of elevations. This minimizes any extrapolation with unsampled LiDAR

340 distributions. However, plot locations were limited by accessibility to areas which could be visited on

341 foot, and there was not a truly independent verification dataset (rather, 10-fold cross validation was

342 used). Because of the low tree species diversity and the wide range sampled, this is likely a minor

343 source of error. Similarly, hydric soils and the riparian zone were delineated via photointerpretation

344 based on morphology and reflectance. Given the remoteness of the region, this is the only feasible

345 approach without relying on modeling products, which entail assumptions that would interfere with the

346 statistical analysis here. Informal observations at each plot supported the soil classifications. Finally,

347 single tree mortality is expected to cause significant random variation at the pixel scale due to variations

348 in tree age and background tree death. This is not a limitation of the LiDAR derived biomass map, which

349 can accommodate those gaps at this scale $\left(400 \mathrm{~m}^{2}\right)$, but does likely add variability to the subsequent

350 evaluation of biomass distributions, as a plot may have low biomass because of topography (for

351 example) or because of a recent treefall. As this is assumed to be both relatively common given the

352 large landscape, and randomly distributed spatially throughout the watershed, this would not bias the

353 distribution analysis towards any particular descriptor variable (though it would be expected to lower

354 final $r^{2}$ values).

355 CONCLUSIONS:

356 Temperate rainforests are unique landscapes comprised of thick forests with very high precipitation

357 rates and little to no history of fire. As a result, biomass (above and belowground) accumulates and 358 carbon stocks reach densities higher than any other global biome (Keith et al. 2009). Understanding

359 how that biomass is distributed at multiple scales is important for a variety of reasons, including 
360 anticipating how climate change will affect these forests and better informing management decisions

361 (e.g., prioritizing certain areas of high biomass accumulation for carbon storage). This study used a

362 synoptic approach, analyzing the entire forest from glacial headwaters to estuarine mouth

363 simultaneously to explore landscape-scale drivers of aboveground biomass distributions. Elevation was,

364 unsurprisingly, strongly correlated with biomass, likely by influencing growing season length and

365 temperature. Beyond that, drainage rates and water accumulation appear to control where biomass is

366 located on the landscape: Areas with high water accumulation and/or poor drainage have little

367 aboveground biomass, whereas better drained locations have higher aboveground biomass. Stand

368 replacing disturbances appear to have had little influence on current biomass distributions, but the data

369 suggest that small-scale, gap formation (single tree mortality) plays a large role in point-to-point

370 variation at this resolution $(20 \mathrm{~m})$. A better understanding of future water balance is therefore needed

371 to successfully anticipate aboveground forest biomass changes due to the shifting climate in this region.

372 ACKNOWLEDGEMENTS:

373 Support for this research was partially from Alaska EPSCoR NSF award \#OIA-1208927, the State of

374 Alaska, and the Alaska Coastal Forest Center with funds from McIntire-Stennis Cooperative Forestry

375 Research Program. Thanks to William Bottorf for field work help and two anonymous reviewers and the 376 editor for their constructive comments. 
408

409

410

\section{References}

Alaback, P.B. 1996. Biodiversity patterns in relation to climate: the coastal temperate rainforests of North America. In High-latitude rainforests and associated ecosystems of the West Coast of the Americas. Springer New York (pp. 105-133)

Bisbing, S.M., Cooper, D.J., D’Amore, D.V., and Marshall, K.N. 2015. Determinants of conifer distributions across peatland to forest gradients in the coastal temperate rainforest of southeast Alaska. Ecohydrology. DOI: 10.1002/eco.1640.

Breiman, L., Friedman, J., Olshen, R., Stone, C., Steinberg, D., and Colla, P. 1983. CART: Classification and regression trees. Wadsworth: Belmont, $C A$.

Brown, J.K. 1974. Handbook for inventorying downed woody material. USDA Forest Service GTR-INT 16. 24 pages.

Brown, J.K. 1976. Estimating shrub biomass from basal stem diameters. Canadian Journal of Forest Research 6(2): 153-158

Buma, B. and Barrett, T.M. 2015. Spatial and topographic trends in forest expansion and biomass change, from regional to local scales. Global Change Biology 21(9): 3445-3454.

Buma, B. and Johnson, A.C. 2015. The role of windstorm exposure and yellow cedar decline on landslide susceptibility in southeast Alaskan temperate rainforests. Geomorphology 228: 504-511.

Carstenson, R. 2013. Natural History of Juneau Trails: A watershed approach. Discovery Southeast. Juneau, AK. 99801.

DellaSala, D.A. 2011. Temperate and boreal rainforests of the world: ecology and conservation. Island Press

Fredeen, A.L., Bois, C.H., Janzen, D.R., and Sanborn, P.T. 2005. Comparison of coniferous forest carbon stocks between old growth and young growth forests on two soil types in central British Columbia, Canada. Canadian Journal of Forest Research 35: 1411-1421.

Friedman, J.H. 1991. Multivariate adaptive regression splines. The Annals of Statistics 19: 1-67.

Guneralp, I., Filippi, A.M., and Randall, J. 2014. Estimation of floodplain aboveground biomass using multispectral remote sensing and nonparametric modeling. International Journal of Applied Earth Observation and Geoinformation 33: 119-126.

Helfield, J.M. and Naiman, R.J. 2003. Effects of salmon-derived nitrogen on riparian forest growth and implications for stream productivity. Ecology 84(12): 3399-3401

Hudak, A.T., Strand, E.K., Vierling, L.A., Byrne, J.C., Eitel, J.U., Martinuzzi, S., and Falkowski, M.J. 2012. Quantifying aboveground forest carbon pools and fluxes from repeat LiDAR surveys. Remote Sensing of Environment 123: 25-40.

Keith, H., Mackey, B.G., and Lindenmayer, D.B. 2009. Re-evaluation of forest biomass carbon stocks and lessons from the world's most carbon-dense forests. PNAS 106(28): 11635-11640 
413

414

415

416

417

418

419

420

421

422

423

424

425

426

427

428

429

430

431

432

433

434

435

436

437

438

439

440

441

442

443

444

445

446

447

448

Keith, H., Mackey, B., Berry, S., Lindenmayer, D. and Gibbons, P., 2010. Estimating carbon carrying capacity in natural forest ecosystems across heterogeneous landscapes: addressing sources of error. Global Change Biology 16(11): 2971-2989.

Keyser, C.E. 2008, revised 2014. Southeast Alaska and Coastal British Columbia (AK) Variant Overview Forest Vegetation Simulator. Internal Rep. Fort Collins, CO: U. S. Department of Agriculture, Forest Service, Forest Management Service Center. 37p.

Kimmins, J.P. 1996. Importance of soil and role of ecosystem disturbance for sustained productivity of cool temperate and boreal forests. Soil Science Society of America Journal 60(6): 1643-1654

Kozak, A., Munro, D.D., and Smith, J.H.G. 1969. Taper functions and their application in forest inventory. The Forestry Chronicle 45(4): 278-283

Kramer, M.G., Sollins, P., and Sletten, R.S. 2004. Soil carbon dynamics across a windthrow disturbance sequence in southeast Alaska. Ecology 85(8): 2230-2244.

Kramer, M.G., Hansen, A.J., Taper, M.L., and Kissinger, E.J. 2001. Abiotic controls on long-term windthrow disturbance and temperate rain forest dynamics in southeast Alaska. Ecology 82(10): 27492768.

Leighty, W.W., Hamburg, S.P., and Caouette, J. 2006. Effects of management on carbon sequestration in forest biomass in Southeast Alaska. Ecosystems 9(7): 1051-1065

Matsuzaki, E., Sanborn, P., Fredeen, A.L., Shaw, C.H. and Hawkins, C., 2013. Carbon stocks in managed and unmanaged old-growth western redcedar and western hemlock stands of Canada's inland temperate rainforests. Forest Ecology and Management 297: 108-119.

Meehl, G.A., Tebaldi, C., and Nychka, D. 2004. Changes in frost days in simulations of twentyfirst century climate. Climate Dynamics 23(5): 495-511.

Mitchard, E.T., Saatchi, S.S., Baccini, A., Asner, G.P., Goetz, S.J., Harris, N.L. and Brown, S., 2013. Uncertainty in the spatial distribution of tropical forest biomass: a comparison of pan-tropical maps. Carbon Balance Management 8(1): no. 10.

Mitchell, S.J. 2012. Wind as a natural disturbance agent in forests: a synthesis. Forestry, cps058.

Muehlbauer, J.D., Collins, S.F., Doyle, M.W., and Tockner, K. 2014. How wide is a stream? Spatial extent of the potential "stream signature" in terrestrial food webs using meta-analysis. Ecology 95(1): 44-55

Nowacki, G.J. and Kramer, M.G. 1998. The effects of wind disturbance on temperate rainforest structure and dynamics of Southeast Alaska. USDA Forest Service GTR 421. 31 pages.

Ott, R.A. and Juday, G.P. 2002. Canopy gap characteristics and their implications for management in the temperate rainforests of southeast Alaska. Forest Ecology and Management 159(3): 271-291

Peterson, R.L., Liang, J., and Barrett, T.M. 2014. Modeling Population Dynamics and Woody Biomass in Alaska Coastal Forest. Forest Science 60(2): 391-401.

R Core Team. 2015. R: A language and environment for statistical computing. R Foundation for Statistical Computing, Vienna, Austria. URL https://www.R-project.org/. 
449 Ray, D. and Nicoll, B.C. 1998. The effect of soil water-table depth on root-plate development and 450 stability of Sitka spruce. Forestry 71(2): 169-182.

451 Simard, M., Lecomte, N., Bergeron, Y., Bernier, P.Y., and Paré, D. 2007. Forest productivity decline 452 caused by successional paludification of boreal soils. Ecological Applications 17(6): 1619-1637

453 Smithwick, E.A., Harmon, M.E., Remillard, S.M., Acker, S.A. and Franklin, J.F., 2002. Potential upper 454 bounds of carbon stores in forests of the Pacific Northwest. Ecological Applications 12(5): 1303-1317.

455 Standish, J.T., Manning, G.H., and Demaerschalk, J.P. 1985. Development of biomass equations for 456 British Columbia tree species (No. BC-X-264)

457 Ter-Mikaelian, M.T. and Korzukhin, M.D. 1997. Biomass equations for sixty-five North American tree 458 species. Forest Ecology and Management 97(1): 1-24

459 Trofymow, J.A. and Blackwell, B.A., 1998. Changes in ecosystem mass and carbon distributions in coastal 460 forest chronosequences. Northwest Science 72: 40-42

461 Ung, C.H., Bernier, P., and Guo, X.J. 2008. Canadian national biomass equations: new parameter 462 estimates that include British Columbia data. Canadian Journal of Forest Research 38(5): 1123-1132.

463 USFS. 2013. Tongass National Forest Soil Inventory. Downloaded 9/2015. Available at 464 seakgis.alaska.edu

465 Veblen, T.T. and Alaback, P.B. 1996. A comparative review of forest dynamics and disturbance in the 466 temperate rainforests of North and South America. In High-Latitude Rainforests and Associated

467 Ecosystems of the West Coast of the Americas. Springer New York (pp. 173-213)

468 Viereck, L.A., Dyrness, C.T., Cleve, K.V., and Foote, M.J. 1983. Vegetation, soils, and forest productivity in 469 selected forest types in interior Alaska. Canadian Journal of Forest Research 13(5): 703-720

470 Waring, R.H. and Franklin, J.F., 1979. Evergreen coniferous forests of the Pacific

471 Northwest. Science, 204: 1380-1386.

472 Wulder, M.A., White, J.C., Nelson, R.F., Næsset, E., Ørka, H.O., Coops, N.C., Hilker, T., Bater, C.W. and 473 Gobakken, T., 2012. Lidar sampling for large-area forest characterization: A review. Remote Sensing of 474 Environment 121: 196-209.

475

476 
Table 1. Variables used in distribution models (elevation was removed via statistical partialling, see Supplementary Data 2). See source for information on derivation.

\begin{tabular}{|c|c|c|}
\hline Variable & Units & Source \\
\hline Aspect & 0 (north) -1 (south) & ASTER DEM \\
\hline Slope & 0-90, Degrees & ASTER DEM \\
\hline Potential Solar Radiation & $0+, W / m^{2}$ & $\begin{array}{c}\text { ASTER DEM (yearly average } \\
\text { based on topographic shading } \\
\text { and latitude) }\end{array}$ \\
\hline Contributing Area & $0+, m^{2}$ & ASTER DEM \\
\hline Topographic Index & $\begin{array}{c}0+, \\
\log (\text { catchment area/tan gradient) }\end{array}$ & ASTER DEM \\
\hline $\begin{array}{l}\text { Exposure to stand replacing } \\
\text { windstorms }\end{array}$ & $\begin{array}{c}0-9 \text { (relative scale). } 0=\text { low, } 9= \\
\text { high }\end{array}$ & $\begin{array}{l}\text { Methods from Kramer et al. } \\
\text { 2001, as implemented by Buma } \\
\text { and Johnson } 2015\end{array}$ \\
\hline Exposure to landslides & 0.0-1.0 (slide suitability) & $\begin{array}{l}\text { Methods from Buma and } \\
\text { Johnson } 2015\end{array}$ \\
\hline $\begin{array}{c}\text { Hydric Soils (soils typically } \\
\text { waterlogged, from } \\
\text { photointerpretation) }\end{array}$ & Yes/No & $\begin{array}{l}\text { Tongass National Forest Soil } \\
\text { Inventory, USFS } 2013\end{array}$ \\
\hline $\begin{array}{l}\text { Riparian area (alluvial soils, } \\
\text { from photointerpretation) }\end{array}$ & Yes/No & $\begin{array}{l}\text { Tongass National Forest Soil } \\
\text { Inventory, USFS } 2013\end{array}$ \\
\hline
\end{tabular}


479 Figure 1. Study area, estimated biomass (Standish allometrics), and biomass sampling points.

480 Figure 2. Predicted aboveground biomass (live, dead, CWD) vs. observed $\left(r^{2}=0.76, n=63\right)$ utilizing the 481 Standish set of allometric equations and histogram of the residuals. Error was normally distributed, with 482 errors $<10 \%$ for the majority of the plots sampled.

483 Figure 3. Modeled aboveground biomass (live, dead, CWD) utilizing the Standish set of allometric 484 equations, with sampling points noted. The discrete patches of low biomass at low elevation 485 correspond to peatlands found in areas of very low slope throughout the region (compare to Fig. 1). 486 Area around the boundary faded to provide contrast.

487 Figure 4. Regression tree results for the Standish allometrics. Both allometrics produced trees that are 488 broadly similar, highlighting the importance of water and drainage throughout the landscape, primarily 489 as a function of slope, soils, and contributing area. Disturbance exposure was included in the trees, 490 though only explaining a minor component of the variation. Landslide suit = Slide suitability $\left(\log _{10}\right)$;

491 Contrib A. = Contributing Area $\left(\log _{10}\right)$; Exposure = Wind Exposure.

492 Figure 5. Slope vs. residual biomass values, after controlling for elevation. Areas of low slope are 493 generally associated with lower biomass than would be expected from their elevation (negative 494 residuals), areas of steeper slopes have higher biomass; that pattern is altered in riparian zones. 
498

499

500

501

502

503

Any study with allometric scaling must consider the sensitivity of the conclusions to different allometric equations, especially those using equations not derived on site. To do so, we utilized two independent sets of regression equations and conducted identical analyses, including creating a MARS model and a CART analysis (as described in the main text). Below is an analysis of the differences between the two ARGs demonstrating minimal differences between the two and the CART regression model for the alternate set of equations.

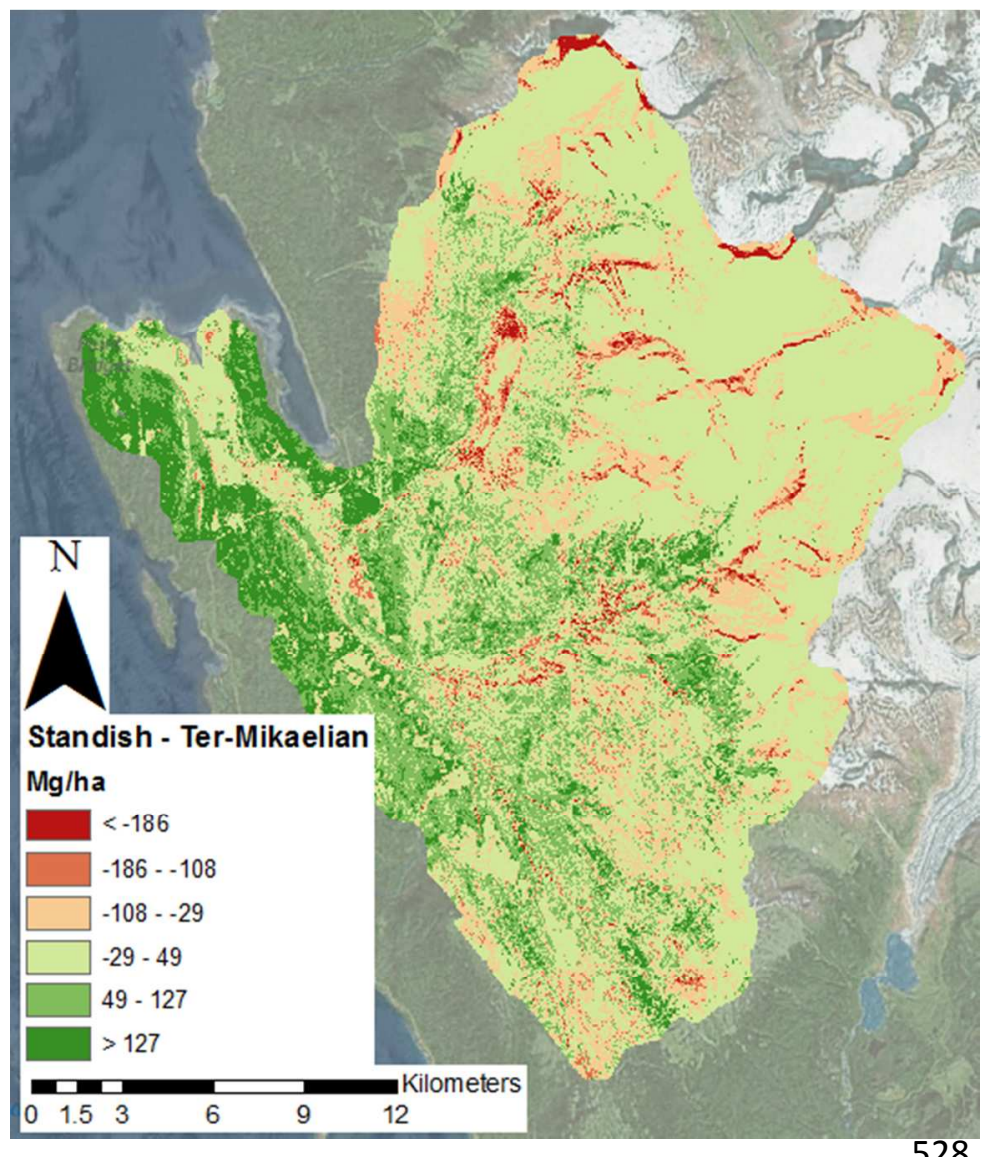

Figure A1-1. Differences between the two biomass maps; 529 positive values show higher estimation by Standish allometrics, negative show higher estimation by TerMikaelian. Mean value of $11.6 \mathrm{Mg} / \mathrm{ha}$, groups are 1 stand $\$ 32$ deviation each.

The Standish and Ter-Mikaelian allometrics were quite similar (mean difference $11.6 \mathrm{Mg} / \mathrm{ha}$, with Standish being larger). This difference was not evenly distributed, with Standish typically predicting higher biomass on hillsides and Ter-Mikaelian higher on flat ground (Fig. A1-1) and the dominant variables identified using the alternative allometrics were very similar (Fig. A1-2). There was also error in areas of smaller trees, such as along the edges of peatlands. This is likely because allometric models are historically biased towards high biomass (and commercially valuable) forest stands and do not handle small trees or non-commercial, peatland species such as shore pine accurately. Both ARGs resulted in some anomalous areas of higher biomass at very high elevations, above treeline. This resulted from cliffs, glacial crevasses, and other rock topography appearing as vertical heterogeneity. This could be removed by analyzing the data at a finer spatial resolution, which would introduce problems in the forest (where tree size and spatial heterogeneity require larger units of analysis); using a variable resolution of analysis (finer scale in non-vegetated locations); or simply eliminating/masking high elevation areas from further consideration, as was done here.

As many areas in temperate rainforests are entering protected status, or are already designated for noncommercial use, future allometric development should likely focus on areas of low biomass to resolve 
540

541

542

543

544

545

546

547

548

mostly controlled by high-volume areas of the landscape, it will increase spatial precision of those estimates.

To confirm that the conclusions were not sensitive to the choice of allometrics, an identical CART analysis was conducted on the secondary allometric dataset. The most important variables were again related to drainage: slope and soils. Wind exposure was the final split retained after tree pruning. Similar to landslides identified in the Standish model, wind exposure is a measure of disturbance potential. The similarity between the CART model variable selection despite the independent allometrics lends support to the conclusion that drainage is the primary variable controlling biomass distribution at the watershed scale.

\section{Aboveground biomass residuals (Mg/ha): Ter-Mikaelian}
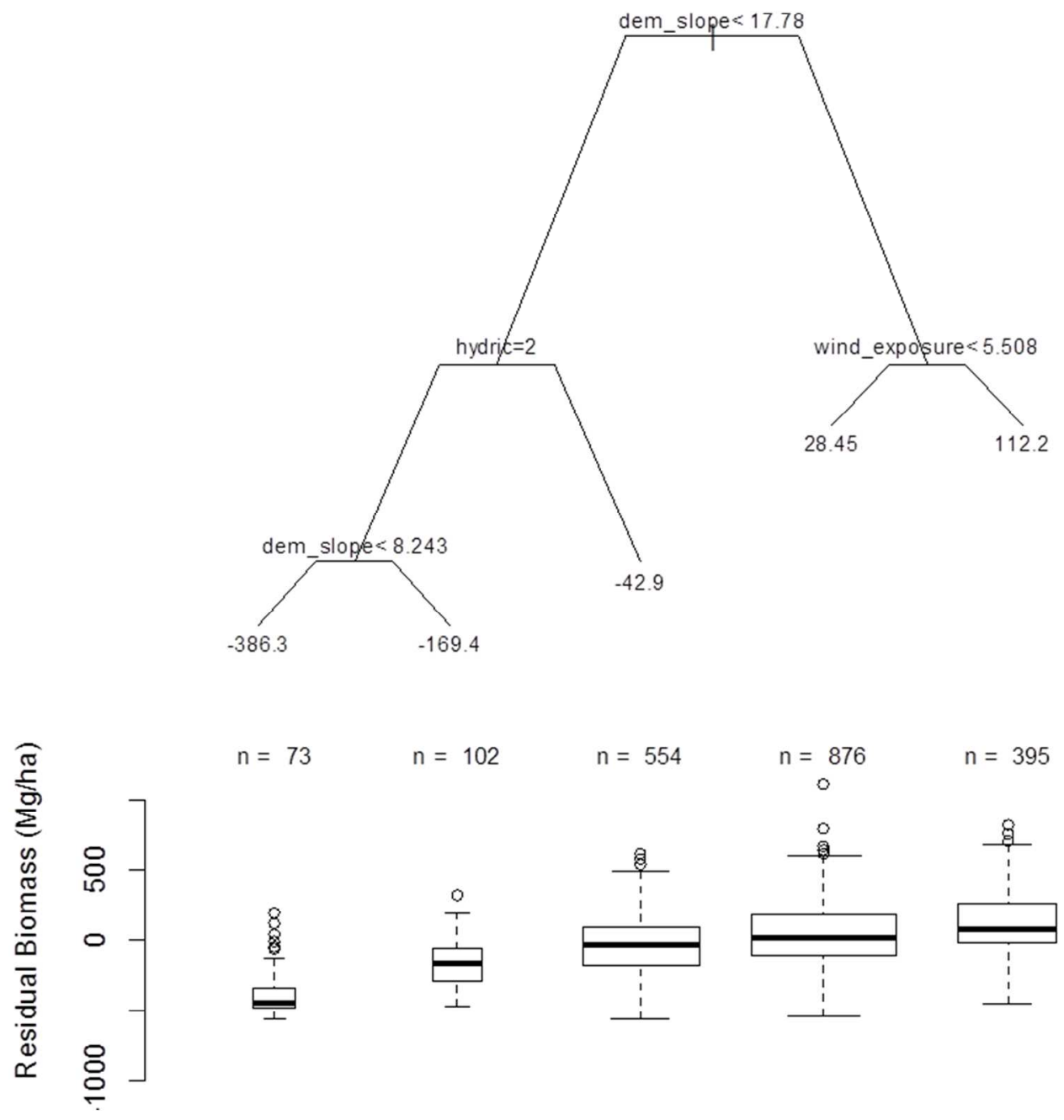

Figure A1-2. CART analysis of the Ter-Mikaleian derived biomass map. Similar to the primary analysis, slope and drainage appear to be the main factors driving biomass distribution across the landscape. 


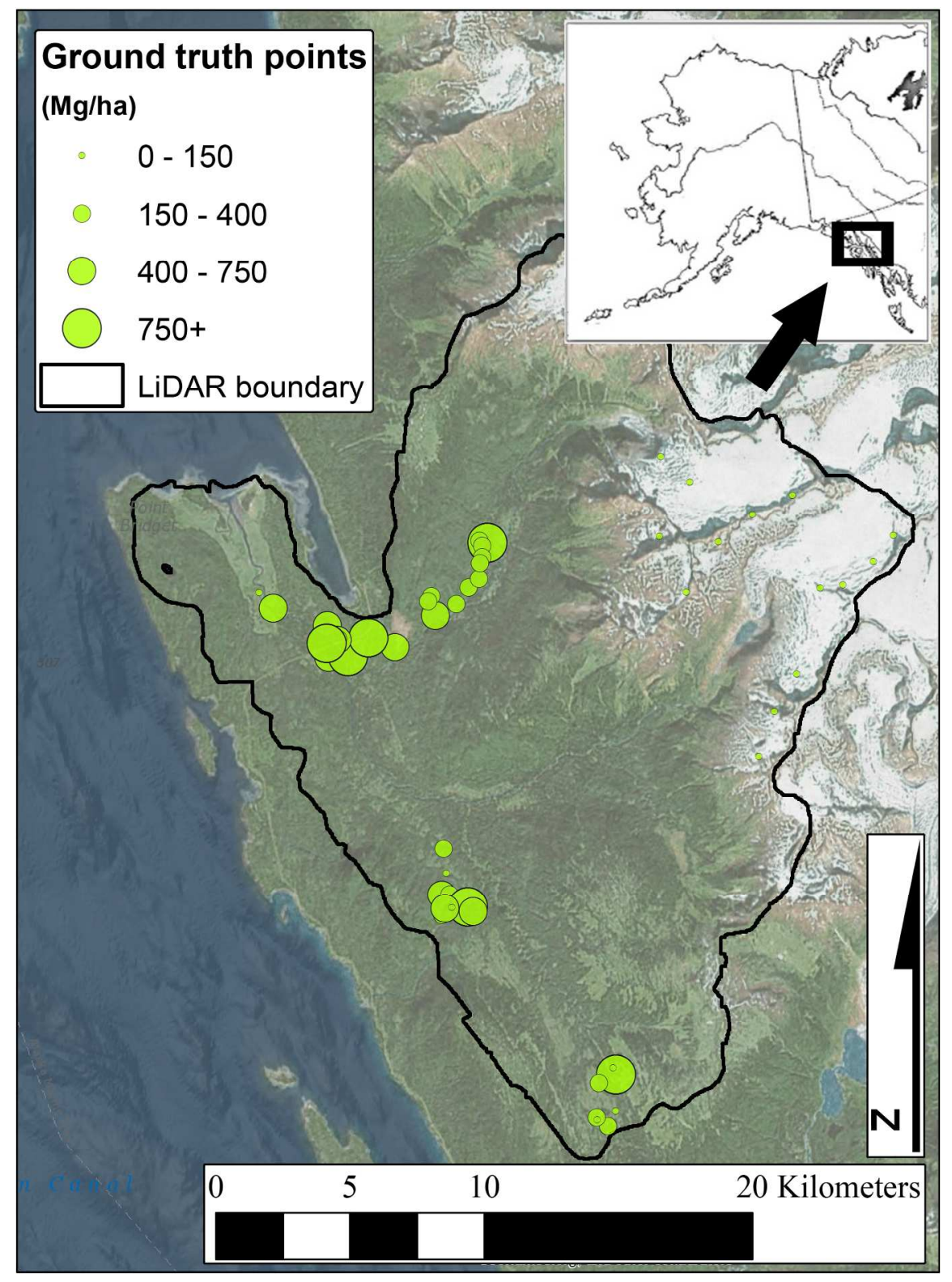

Figure 1

$172 \times 235 \mathrm{~mm}(300 \times 300 \mathrm{DPI})$ 


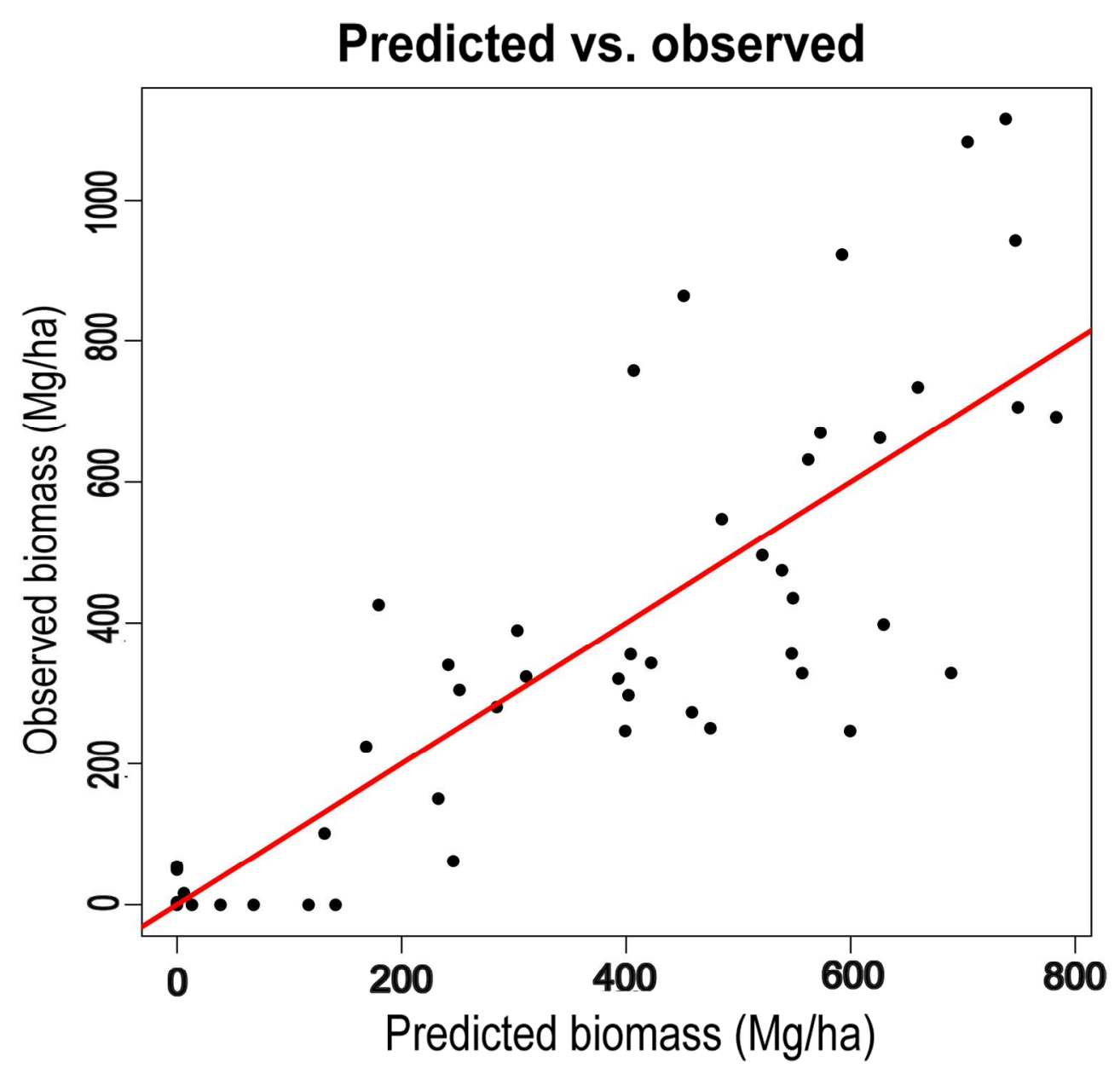

Figure 2

$171 \times 166 \mathrm{~mm}(300 \times 300 \mathrm{DPI})$ 


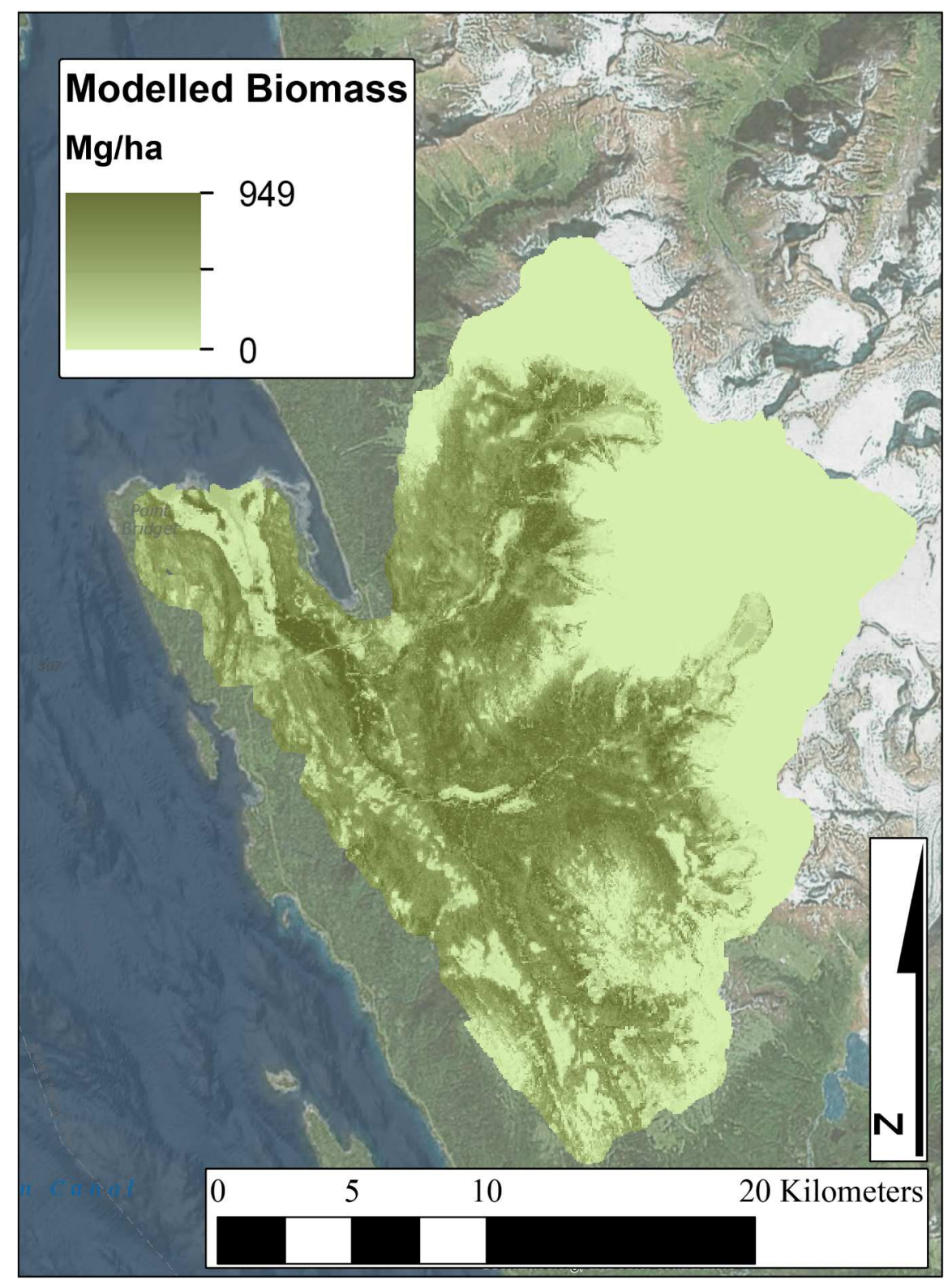

Figure 3

$172 \times 235 \mathrm{~mm}(300 \times 300$ DPI $)$ 
Aboveground Biomass Residuals (Mg/ha): Standish Allometrics

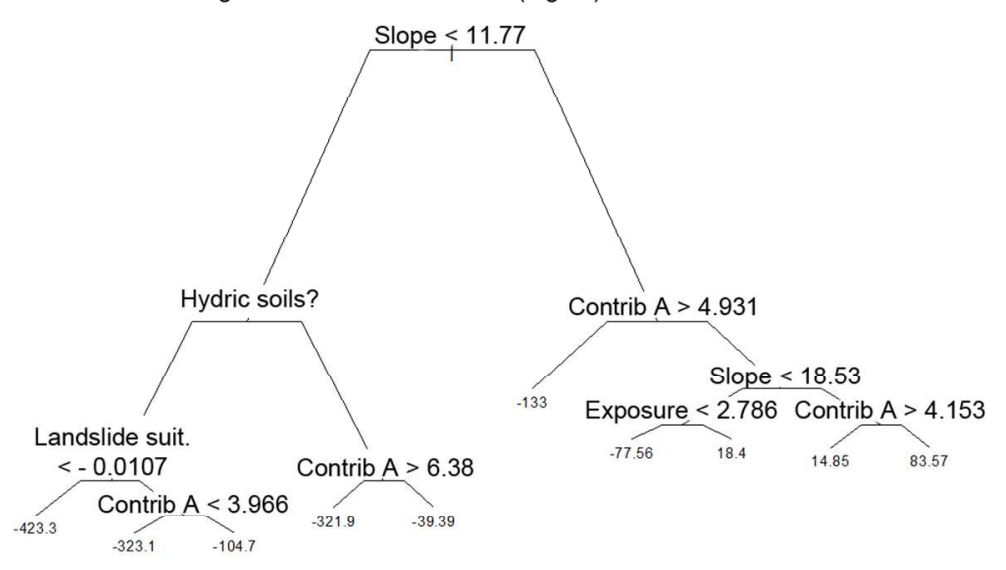

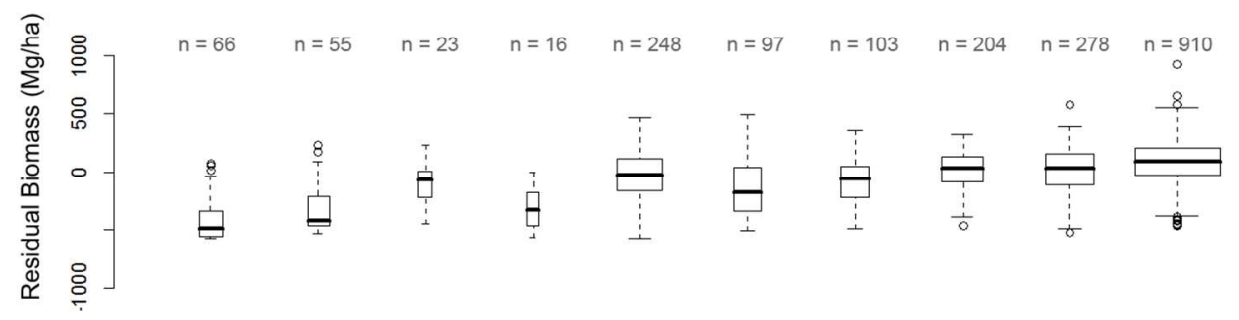

Figure 4

$112 \times 84 \mathrm{~mm}(300 \times 300$ DPI $)$ 


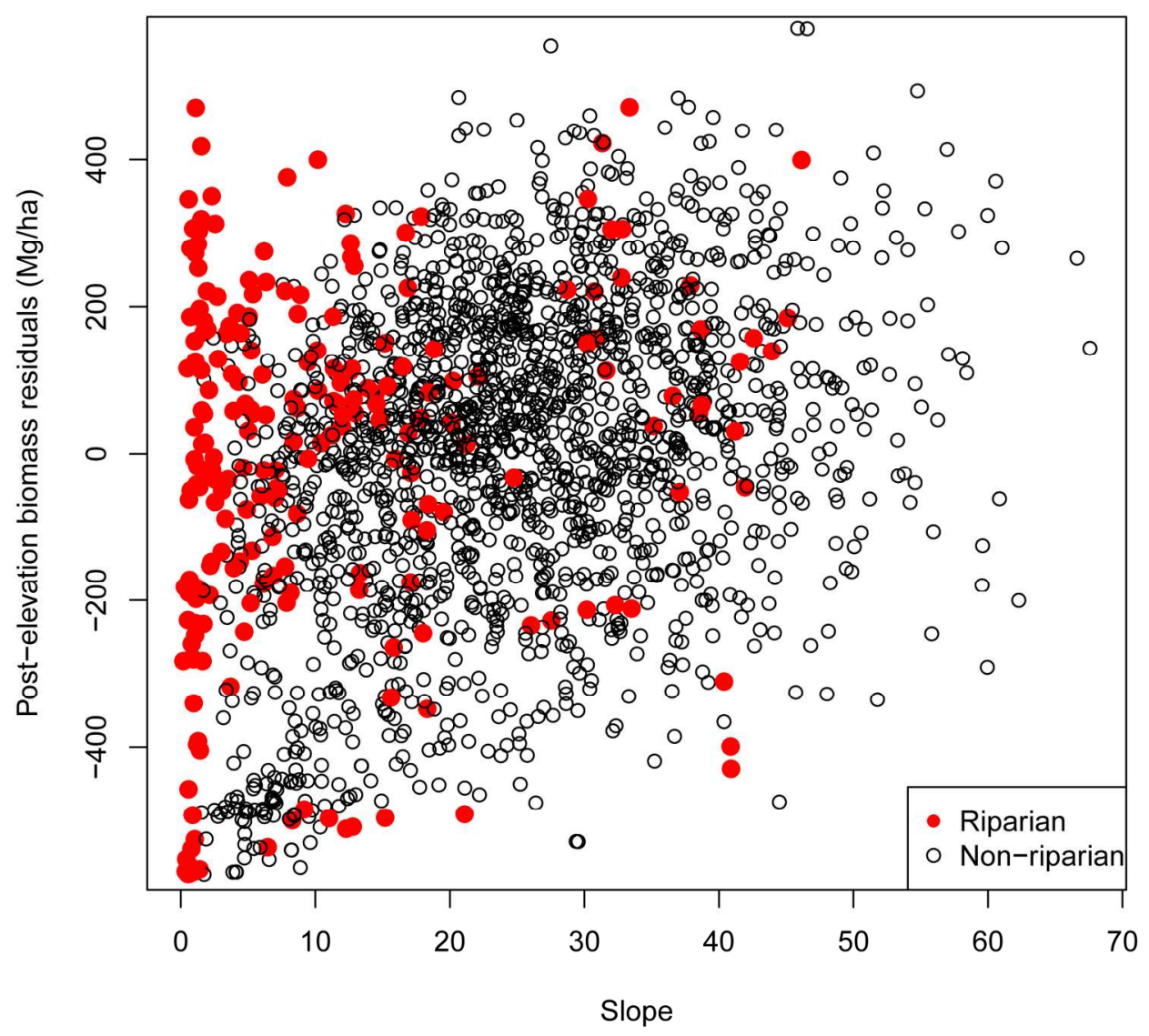

Figure 5

$175 \times 151 \mathrm{~mm}(300 \times 300$ DPI $)$ 